\title{
Observational Study of the Use of Insulin Glargine as Basal Therapy in Patients With Type 2 Diabetes Mellitus in Morocco
}

\author{
Abdelmjid Chraibi ${ }^{a}$, d, Hinde Iraqi ${ }^{a}$, Mehdi Seqat ${ }^{b}$, Youness El Achhab ${ }^{c}$, \\ Chakib Nejjaric
}

\begin{abstract}
Background: The aim of the study was to assess the real-life efficacy and safety of insulin glargine (Lantus ${ }^{\circledR}$, Sanofi) as a basal regimen in patients with type 2 diabetes mellitus (T2DM) who are poorly controlled with oral antidiabetic drugs (OADs) and/or other insulins.

Methods: This observational, multicenter study was carried out in Morocco in 2011 and included 497 adult patients with T2DM and a baseline glycated hemoglobin (HbAlc) between $7.5 \%$ and $10.5 \%$ and for whom a basal regimen with insulin glargine was initiated. Two follow-up visits were scheduled at 12 and 26 weeks after starting treatment. The primary outcome target was HbA1c $<7 \%$. Safety was assessed by the frequency of hypoglycemic episodes.

Results: The target HbA1c level of $<7 \%$ was reached by $11.5 \%$ of patients after 3 months of insulin glargine treatment and 32\% after 6 months. Mean HbA1c decreased significantly from $9.37 \pm 1.14 \%$ at baseline to $7.43 \pm 0.87 \%$ at 6 months $(\mathrm{P}<0.001)$. Mean fasting blood glucose also decreased significantly from $237.5 \pm 66.9 \mathrm{mg} / \mathrm{dL}$ at baseline to $129.5 \pm 35.1 \mathrm{mg} / \mathrm{dL}$ at 6 months $(\mathrm{P}<0.001)$. Approximately $12 \%$ of patients reported at least one hypoglycemic episode. No adverse event other than hypoglycemia was reported.
\end{abstract}

Conclusions: This study shows that in a real-life setting, a basal regimen with insulin glargine significantly improves glycemic control in patients with T2DM who are inadequately controlled with OADs or other insulin regimens, with an acceptable hypoglycemia profile.

Keywords: Insulin glargine; Glycemic control; Basal regimen; Type 2 diabetes mellitus; Glycated hemoglobin; Fasting blood glucose

Manuscript accepted for publication October 21, 2015

a'Department of Endocrinology and Diabetology, Ibn Sina Hospital, Rabat, Mohammed V University, Rabat, Morocco

${ }^{b}$ Medical Affairs Department, Sanofi Maroc, Casablanca, Morocco

${ }^{\circ}$ Epidemiology and Clinical Research Department, Sidi Mohammed Benabdellah, University Hospital, Fez, Morocco

${ }^{\mathrm{d} C}$ Corresponding Author: Abdelmjid Chraibi, Department of Endocrinology and Diabetology, Ibn Sina Hospital, Mohammed V University, Rabat, Morocco.Email: abdelmjid.chraibi7@gmail.com

doi: http://dx.doi.org/10.14740/jem315w

\section{Introduction}

Type 2 diabetes mellitus (T2DM) is the most common metabolic disorder worldwide and results from the combination of abnormal secretion and action of insulin [1]. Achieving and maintaining a target glycated hemoglobin (HbA1c) level of $<$ $7 \%$ in patients with $\mathrm{T} 2 \mathrm{DM}$ reduces the risk of developing diabetes complications, particularly microvascular complications such as nephropathy, retinopathy and neuropathy [2]. However, prospective studies have shown that many patients in routine medical practice do not achieve optimal glycemic control [3-5]. International guidelines emphasize the importance of early initiation of T2DM therapies, particularly the initiation of insulin therapy, in patients who are poorly controlled with other antidiabetic medications, to modify the course of hyperglycemia and to prevent or delay the development of long-term complications [2,6]. Assessing the real-life use of therapeutic alternatives to standard insulin regimens is extremely important.

In Morocco, few data are available on the efficacy and safety of insulin therapy in patients with T2DM. The aim of this prospective, observational study was to assess the efficacy and safety of long-acting insulin glargine (Lantus ${ }^{\circledR}$, Sanofi) in T2DM patients who were inadequately controlled with oral antidiabetic drug (OAD) therapies or other types of insulin.

\section{Materials and Methods}

\section{Study design and patients}

This national, multicenter, observational study took place between May 2010 and June 2011. A total of 50 randomly selected endocrinologists-diabetologists across Morocco were asked to participate in the study. Patients with T2DM were enrolled if they fulfilled the following inclusion criteria: adults (male or female) aged $\geq 18$ years with uncontrolled T2DM, HbA1c between $7.5 \%$ and $10.5 \%$ despite antidiabetic treatment in addition to lifestyle and dietary measures conducted for at least 6 months, and basal insulin therapy initiated. Participating physicians recruited the first 10 patients meeting all inclusion criteria. All eligible patients gave their signed informed consent to take part in the study. 
Table 1. Characteristics of the Study Population at Inclusion (Baseline)

\begin{tabular}{|c|c|}
\hline \multicolumn{2}{|l|}{ Characteristic } \\
\hline \multicolumn{2}{|l|}{ Sex } \\
\hline Male/female & $220 / 274(44.5 / 55.5)$ \\
\hline Age (years) & $57.5 \pm 10.3$ \\
\hline \multicolumn{2}{|l|}{ Age group (years) } \\
\hline $18-40$ & $15(3.1)$ \\
\hline $41-50$ & $98(20.0)$ \\
\hline $51-60$ & $185(37.7)$ \\
\hline $61-70$ & $133(27.1)$ \\
\hline$>70$ & $60(12.2)$ \\
\hline Duration of diabetes (years) & $9.8 \pm 6.1$ \\
\hline \multicolumn{2}{|l|}{ Body mass index } \\
\hline$<25 \mathrm{~kg} / \mathrm{m}^{2}$ & $118(25.3)$ \\
\hline $25-30 \mathrm{~kg} / \mathrm{m}^{2}$ & $230(49.1)$ \\
\hline$>30 \mathrm{~kg} / \mathrm{m}^{2}$ & $120(25.6)$ \\
\hline \multicolumn{2}{|l|}{ Insulin therapy } \\
\hline Initiation of insulin glargine & $388(78.1)$ \\
\hline $\begin{array}{l}\text { Modification of insulin (change } \\
\text { to insulin glargine) }\end{array}$ & $109(21.9)$ \\
\hline
\end{tabular}

All values shown are $\mathrm{n}(\%)$, or mean $\pm \mathrm{SD}$.

Patients aged $<18$ years, those with known hypersensitivity to glargine, pregnant or breastfeeding women were excluded from the study. Taking into account a $25 \%$ expected control rate, $4 \%$ precision and $20 \%$ dropout, the calculated sample size was 495 patients.

\section{Treatment}

Only patients given basal therapy with insulin glargine were included in the analysis. Patients were treated with insulin glargine $(100 \mathrm{IU} / \mathrm{mL}$ solution for subcutaneous injection) at the physician's discretion and according to local Summary of Product Characteristics (SmPC) requirements. According to local SmPC, insulin glargine is administrated subcutaneously once a day at any time but at the same time each day. The dosage and timing of insulin glargine doses is titrated and individually adjusted to achieve fasting blood glucose (FBG) levels of $<130 \mathrm{mg} / \mathrm{dL}$ according to the ADA/EASD consensus algorithm published in January 2009 [6].

\section{Data collected}

Data for each patient were collected by the participating physicians using a standardized questionnaire at each visit. All patients had three visits: an initial inclusion (baseline) visit and two follow-up visits at week 12 and week 26 after inclusion. The total duration of the study for each patient was 6 months.
Table 2. Changes in Antidiabetic Treatments Over the 6-Month Study Period

\begin{tabular}{|lll}
\hline & $\begin{array}{l}\text { Week 12 } \\
\text { (visit 2) }\end{array}$ & $\begin{array}{l}\text { Week 26 } \\
\text { (visit 3) }\end{array}$ \\
\hline Total number of OAD changes & $150 / 477(31.4)$ & $57 / 454(12.6)$ \\
\hline \multicolumn{1}{c}{ OAD stopped } & $98 / 477(20.5)$ & $37 / 454(8.1)$ \\
$\quad$ OAD added & $87 / 477(18.2)$ & $31 / 442(7.0)$ \\
Sulphonylureas stopped & $48 / 477(10.1)$ & $16 / 454(3.5)$ \\
Biguanides stopped & $28 / 477(5.9)$ & $16 / 454(3.5)$ \\
Insulin glargine & & \\
$\quad$ Dose changed & $398 / 484(82.2)$ & $225 / 470(47.9)$ \\
$\quad$ Rapid insulin added & $45 / 484(9.3)$ & $33 / 470(7.0)$ \\
\hline
\end{tabular}

Results are shown as n (\%). OAD: antidiabetic drugs.

The following data were collected at baseline: age, sex, weight, height, waist circumference, duration of diabetes, previous treatments, duration of insulin therapy, doses of insulin, FBG and HbA1c level; and at the two follow-up visits: weight, waist circumference, HbA1c level, FBG, dose of insulin glargine administered, addition of another insulin dose, oral medications and their doses (if applicable), hypoglycemic events and their characteristics (symptomatic, severely symptomatic, and diurnal/nocturnal).

\section{Objectives}

The primary objective was to describe the proportion of T2DM patients with $\mathrm{HbA} 1 \mathrm{c}<7 \%$ after 6 months of real-life treatment with insulin glargine. The secondary objective was to describe number of hypoglycemic events.

\section{Statistical analysis}

A descriptive analysis was performed on the socio-demographic, clinical and therapeutic characteristics of the patients. Classic tests for paired samples (Student's t-test and MacNemar test) were used to compare qualitative and quantitative variables between baseline and each visit. A P value of $<0.05$ was considered statistically significant.

SPSS version 17.0 was used for all statistical analyses.

\section{Results}

\section{Study population}

A total of 50 centers across Morocco took part in the study and 498 patients were enrolled. Data were available for 497 (99.8\%) of these patients. Mean age was $57.5 \pm 10.3$ years, $55.5 \%$ of the patients were female and mean duration of diabetes was $9.8 \pm$ 6.1 years (Table 1). Using the WHO body mass index (BMI) classification, $74.7 \%$ of patients were overweight or obese. 
Table 3. Evolution of Efficacy Outcome Measures During the 6-Month Study Period

\begin{tabular}{lllllc} 
& Inclusion & Week 12 & Week 26 & \multicolumn{2}{c}{ P } \\
\cline { 5 - 6 } & & & I-W12 & I-W26 \\
\hline HbA1c $\leq 7 \%$ & $0(0)$ & $55(11.5)$ & $149(32.0)$ & & \\
FBA1c $(\%)$ & $9.37 \pm 1.14$ & $8.08 \pm 1.03$ & $7.43 \pm 0.87$ & $<0.001$ & $<0.001$ \\
\hline
\end{tabular}

Values shown are $n(\%)$, or mean \pm SD. FBG: fasting blood glucose.

\section{Antidiabetic treatments}

At baseline, 388 patients $(78.1 \%)$ were being treated with OADs alone and $109(21.9 \%)$ were receiving insulin other than insulin glargine (61 on insulin + OADs and 48 on insulin alone). Among the 109 patients receiving insulin, 53 (48.6\%) patients were on a basal regimen, $11(10.1 \%)$ were on a basal + prandial regimen and $39(35.8 \%)$ were being treated with premixed insulins. Data were not available for six patients. All patients were started on a basal insulin glargine regimen at a mean dose of $17.2 \pm 6.8 \mathrm{IU} /$ day.

The treatment changes in these patients over the 6-month follow-up period are shown in Table 2. OAD treatment was changed in $31.4 \%$ of patients at visit 2 and in $12.6 \%$ of patients at visit 3 . Insulin glargine doses were changed in $82.2 \%$ of patients at visit 2 and in $47.9 \%$ at visit 3 . The mean daily dose of insulin glargine was increased significantly $(\mathrm{P}<0.001)$ during follow-up (17.2 $\pm 6.8 \mathrm{IU}$ at baseline, $22.5 \pm 6.8 \mathrm{IU}$ at visit 2 and $24.4 \pm 7.3 \mathrm{IU}$ at visit 3 ). Rapid insulin was added to the basal regimen in $9.3 \%$ of patients at visit 2 and in $7.0 \%$ of patients at visit 3 .

\section{Efficacy outcome measures}

The evolution of HbAlc levels after initiation of insulin glargine in insulin-naive patients or continuing/changing insulin therapy to insulin glargine in patients previously treated with insulin is shown in Table 3 . Regarding the primary endpoint, $11.5 \%(55 / 477)$ of patients reached the target $\mathrm{HbA} 1 \mathrm{c}$ of $<7 \%$ after 12 weeks of treatment and 32.0\% (149/465) after 26 weeks. Mean HbA1c decreased significantly from $9.37 \pm 1.14 \%$ to $8.08 \pm 1.03 \%(\mathrm{P}<0.001)$ after 12 weeks of treatment with insulin glargine and to $7.43 \pm 0.87 \%(\mathrm{P}<0.001)$ after 26 weeks. Overall, mean HbA1c was reduced by $1.9 \pm 1.2 \%$ from baseline to the last visit at week $26(\mathrm{P}<0.001)$. Mean FBG also decreased significantly from $237.5 \pm 66.9 \mathrm{mg} / \mathrm{dL}$ at baseline to $129.5 \pm 35.1 \mathrm{mg} / \mathrm{dL}$ at week $26(\mathrm{P}<0.001)$, which represented an overall reduction of $108.1 \pm 69.8 \mathrm{mg} / \mathrm{dL}$.

\section{Safety}

A total of 471 patients were included in the safety analysis. Safety data were missing for the other 27 patients. Forty-six patients $(9.8 \%)$ reported episodes of hypoglycemia between inclusion and visit 2 and $55(12 \%)$ between visit 2 and visit 3 . Diurnal and nocturnal hypoglycemia episodes were reported by 33 and 21 patients respectively at visit 2 and 37 and 28 patients respectively at visit 3 . Symptomatic hypoglycemia was reported by 35 patients at visit 2 and 38 patients at visit 3. Three patients reported severe episodes of hypoglycemia at visit 3 but no severe hypoglycemia was reported during visit 2 . The outcome of these three patients was not documented. No adverse event other than hypoglycemia was reported during the study period.

The mean body weight of the patients increased significantly from $76.1 \pm 12.3 \mathrm{~kg}$ at inclusion to $77.2 \pm 11.8 \mathrm{~kg}$ at visit 3 , an increase of $1.3 \pm 3.8 \mathrm{~kg}(\mathrm{P}<0.001)$.

\section{Discussion}

This observational study reports the efficacy and safety of insulin glargine in T2DM patients in Morocco who were inadequately controlled with other antidiabetic treatments and required optimal basal insulin therapy. The results show that, in a real-life setting, a basal regimen with insulin glargine is associated with a significant reduction in mean HbA1c levels and in mean FBG.

These results confirm those observed in clinical studies with insulin glargine conducted in other countries [7]. In the present study, treatment of T2DM patients with insulin glargine for 6 months was associated with a reduction in $\mathrm{HbA} 1 \mathrm{c}$ of $1.9 \pm 1.2 \%$ and a reduction in FBG of $108.1 \pm 69.8 \mathrm{mg} / \mathrm{dL}$. The percentage of patients with controlled diabetes $(\mathrm{HbA} 1 \mathrm{c} \leq 7 \%)$ was $11.5 \%$ at visit 2 (3 months) and $32.0 \%$ at visit 3 (6 months) after the initiation of insulin glargine. A recent real-life study carried out in France [8] reported that the mean HbA1c level decreased from $8.3 \%$ at baseline to $7.8 \%$ a month after the initiation of insulin glargine and to $7.5 \%$ at the end of followup (12 months). The proportion of patients with $\mathrm{HbA} 1 \mathrm{c}<7 \%$ increased from $19.9 \%$ to $33.4 \%$ after the initiation of insulin glargine in patients previously treated with insulin and from $13.9 \%$ to $39.1 \%$ in insulin-naive patients [8]. Similar results were reported in other recent observational studies [9-11]. The mean daily dose of insulin glargine at 6 months was $24.4 \pm 7.3$ IU. This dose is inferior to the doses used in western countries. Further studies may be needed to explain this difference.

The safety of insulin glargine has been assessed in several studies in patients with T2DM, usually in comparison with NPH insulin [8-13]. In general, phase III clinical studies have shown a decreased incidence of hypoglycemia (including severe hypoglycemia requiring the intervention of a third person), especially nocturnal hypoglycemia. In the present study, $12 \%$ of patients reported hypoglycemic episodes during 
the follow-up period but only three patients $(0.6 \%)$ reported severe episodes of hypoglycemia after 6 months of treatment. The outcome of these three patients is not known. Insulin glargine treatment is often associated with a minor gain in body weight $[8,14]$. In the present study, the mean weight gain was $1.3 \mathrm{~kg}$ during the 6-month follow-up period. This compares with $0.8 \mathrm{~kg}$ in the ATLANTUS study [14] and $0.7 \mathrm{~kg}$ in the French study [8].

In conclusion, this observational study conducted in Morocco shows that, in a real-life setting, a basal regimen with insulin glargine significantly improves glycemic control in patients with T2DM who are poorly controlled with OAD medications or other insulin regimens, with an acceptable hypoglycemia profile.

\section{Acknowledgement}

The authors thank Newmed Publishing Services, France, for medical writing services.

\section{Grant Support}

Sanofi Maroc provided funding for the collection of registry data and for medical writing services.

\section{Conflicts of Interest}

A.C. and H.I. received grant support and/or served as consultants for Sanofi, Eli Lilly, Novo Nordisk, Servier, MSD, Abbott, Novartis and AstraZeneca. Y.E. and C.N. declare no conflicts of interest. M.S. is an employee of Sanofi Maroc.

\section{References}

1. Kahn CR. Banting Lecture. Insulin action, diabetogenes, and the cause of type II diabetes. Diabetes. 1994;43(8):1066-1084.

2. Stolar M. Glycemic control and complications in type 2 diabetes mellitus. Am J Med. 2010;123(3 Suppl):S3-11.

3. Ringborg A, Cropet C, Jonsson B, Gagliardino JJ, Ramachandran A, Lindgren P. Resource use associated with type 2 diabetes in Asia, Latin America, the Middle East and Africa: results from the International Diabetes Management Practices Study (IDMPS). Int J Clin Pract. 2009;63(7):997-1007.

4. Farouqi A, Harti MA, Nejjari C. Management of diabetes in Morocco: Results of the International Diabetes Management Practices Study (IDMPS) C Wave 2. Medecine des Maladies Metaboliques 2010;4:704-711.

5. Al-Elq AH. Current practice in the management of patients with type 2 diabetes mellitus in Saudi Arabia. Saudi Med J. 2009;30(12):1551-1556.

6. Nathan DM, Buse JB, Davidson MB, Ferrannini E, Holman RR, Sherwin R, Zinman B. Medical management of hyperglycemia in type 2 diabetes: a consensus algorithm for the initiation and adjustment of therapy: a consensus statement of the American Diabetes Association and the European Association for the Study of Diabetes. Diabetes Care. 2009;32(1):193-203.

7. Goykhman S, Drincic A, Desmangles JC, Rendell M. Insulin Glargine: a review 8 years after its introduction. Expert Opin Pharmacother. 2009;10(4):705-718.

8. Charbonnel B, Eschwege E, Charpentier G, Vialettes B, Chabrier G, Pouchain D, Suissa S, et al. Insuline glargine en conditions reelles d'utilisation en France: Etude observationnelle menee sur une large population de patients diabétiques de type 1 et de type 2. Medecine des Maladies Metaboliques. 2010;4:169-178.

9. Delgado E. Outcomes with insulin glargine in patients with type 2 diabetes previously on NPH insulin: evidence from clinical practice in Spain. Int $\mathrm{J}$ Clin Pract. 2012;66(3):281-288.

10. Xie L, Wei W, Pan C, Du J, Baser O. A real-world study of patients with type 2 diabetes initiating basal insulins via disposable pens. Adv Ther. 2011;28(11):1000-1011.

11. Hajos TR, Pouwer F, de Grooth R, Holleman F, Twisk JW, Diamant M, Snoek FJ. Initiation of insulin glargine in patients with Type 2 diabetes in suboptimal glycaemic control positively impacts health-related quality of life. A prospective cohort study in primary care. Diabet Med. 2011;28(9):1096-1102.

12. Yki-Jarvinen H, Dressler A, Ziemen M. Less nocturnal hypoglycemia and better post-dinner glucose control with bedtime insulin glargine compared with bedtime NPH insulin during insulin combination therapy in type 2 diabetes. HOE 901/3002 Study Group. Diabetes Care. 2000;23(8):1130-1136.

13. Rosenstock J, Schwartz SL, Clark CM, Jr., Park GD, Donley DW, Edwards MB. Basal insulin therapy in type 2 diabetes: 28-week comparison of insulin glargine (HOE 901) and NPH insulin. Diabetes Care. 2001;24(4):631636.

14. Davies M, Sinnassamy P, Storms F, Gomis R. Insulin glargine-based therapy improves glycemic control in patients with type 2 diabetes sub-optimally controlled on premixed insulin therapies. Diabetes Res Clin Pract. 2008;79(2):368-375. 